\section{MICROBIAL RESISTANCES: A PREDICTIVE TEST FOR STREPTOTHRICIN ANTIBIOTICS}

\author{
R. J. Mehta, Y. K. OH, R. D. Sitrin, \\ E. A. Shultis and C. H. NAsh, III \\ Smith Kline \& French Laboratories, \\ U.S. Research, P.O. Box 7929, Philadelphia, \\ PA 19101, U.S.A.
}

(Received for publication May 23, 1981)

One of the major obstacles in the discovery of new antibiotics is the absence of a method for rapid recognition of known compounds. The use of microbes resistant to specific groups of antibiotics as a means of eliminating these compounds was proposed in 1946 by EISMAN, et al. ${ }^{1)}$ and more extensively utilized by STAPLEY ${ }^{2)}$. In a conventional screening program, based on detection of activity against Gram-negative microbes, streptothricin antibiotics are commonly encountered. These antibiotics typically contain streptolidine or methyl streptolidine, L-gulosamine or similar amino sugar and amino acids, frequently $\beta$-lysine. ${ }^{3)}$ We investigated several pairs of streptothricin resistant and sensitive strains including a streptothricin resistant $\left(s t n^{\mathrm{R}}\right)$ mutant of Escherichia coli as presumptive methods for early identification of this group of antibiotics.

The susceptibility of five pairs of test strains, each of which contains a streptothricin sensitive and resistant microbe, to various basic antibiotics was compared by standard agar diffusion assay. These data are shown in Table 1. The Rhodotorula sp. (SK\&F culture collection), Candida albicans (SK\&F culture collection), Bacillus subtilis ATCC 6633, and B. mycoides ATCC 6462, were identified as streptothricin sensitive and resistant pairs. Based on the hypothesis that a microorganisms which produces a specific antibiotic would concurrently be resistant to that antibiotic, we used Streptomyces sp. BC-1143, a streptothricin producer and Streptomyces sp. BC-494, a non-producer, as a test pair. The sensitivity of the Streptomyces sp. BC-1143 was also compared with the sensitive Staphylococcus aureus strain 209P ATCC 6538 P (commonly used as a Gram-positive test strain). A streptothricin resistant mutant $\left(s t n^{\mathrm{R}}\right)$ of Escherichia coli $\mathrm{K} 802 \mathrm{~N}$ isolated after ethylmethane sulfonate treatment was also used as a test strain. The resistant patterns of five pairs of test strains except the $B$. subtilis-B. mycoides pair were consistent with all the streptothricin antibiotics tested in this study.

Table 1. Combination of streptothricin (Stn) sensitive and resistant microbes for the preliminary identification of streptothricin antibiotics. ${ }^{\mathrm{a}}$

\begin{tabular}{|c|c|c|c|c|c|}
\hline \multirow[b]{2}{*}{ Antibiotic tested $^{\mathrm{c}}$} & \multicolumn{5}{|c|}{$\begin{array}{l}\text { Difference in zone of inhibition (mm) } \\
\text { between sensitive and resistant strains }\end{array}$} \\
\hline & $\begin{array}{l}\text { Rhodotorula sp./ } \\
\text { Candida albicans }\end{array}$ & $\begin{array}{l}\text { Bacillus subtilis/ } \\
\text { Bacillus mycoides }\end{array}$ & $\begin{array}{c}\text { Streptomyces sp. } \\
\text { BC 494C (Stn } \\
\text { non-producer)/ } \\
\text { Streptomyces sp. } \\
\text { BC } 1143 \\
\text { (Stn producer) }\end{array}$ & $\begin{array}{c}\text { Staphylococcus } \\
\text { aureus 209P/ } \\
\text { Streptomyces sp. } \\
\text { BC } 1143 \\
\text { (Stn producer) }\end{array}$ & $\begin{array}{c}\text { E. coli } \\
\text { K802N/ } \\
\text { E. coli } \\
802 \mathrm{~N} \text { stn }^{\mathrm{R}}\end{array}$ \\
\hline LLAB $664 \beta$ & 15 & 3 & 30 & 25 & 20 \\
\hline LLAB $664 \alpha$ & 15 & 27 & 31 & 31 & 25 \\
\hline Streptothricin & 18 & 16 & 30 & 30 & 25 \\
\hline Gentamicin & 0 & 15 & 2 & 3 & 0 \\
\hline Kanamycin & 0 & 20 & 1 & 0 & 0 \\
\hline Streptomycin & 0 & 3 & 0 & 0 & 0 \\
\hline Neomycin & 0 & 2 & 0 & 0 & 0 \\
\hline Hygromycin & 0 & 0 & 0 & 0 & 0 \\
\hline Edeine & 0 & 0 & 0 & 0 & 0 \\
\hline
\end{tabular}

a All the strains used were grown overnight in trypticase soy broth (BBL) at $30^{\circ} \mathrm{C}$ on a rotary shaker (250 $\mathrm{rpm}$ ). Seeded assay plates were prepared by adding appropriate dilution of culture to trypticase soy agar. Antibiotic activity (disc diffusion assay) was detected by standard test plates after 24 hours.

b Assayed by disc diffusion method with seeded plate.

c Known antibiotic concentrations were $200 \mu \mathrm{g} / \mathrm{ml}$. 
Table 2. Biological and chemical methods for identification of the streptothricin antibiotics.

\begin{tabular}{|c|c|c|c|c|c|c|}
\hline \multirow{3}{*}{\multicolumn{2}{|c|}{$\begin{array}{c}\text { Known antibiotics } \\
\& \text { fermentation } \\
\text { products }^{\mathrm{a}}\end{array}$}} & \multicolumn{5}{|c|}{ Differential susceptibility ${ }^{b}$} \\
\hline & & \multirow{2}{*}{$\begin{array}{l}\text { E. coli } \\
\mathrm{K} 802 \mathrm{~N} / \\
E . \text { coli } \\
\mathrm{K} 802 \mathrm{~N} \\
\text { stn }^{\mathrm{R}}\end{array}$} & \multirow{2}{*}{$\begin{array}{l}\text { S. aureus } \\
209 \mathrm{P} / \\
\text { Streptomyces } \\
\text { BC } 1143 \\
\text { Stn producer }\end{array}$} & \multicolumn{2}{|c|}{ Amino acid analysis $^{\mathrm{d}}$} & \multirow{2}{*}{$\begin{array}{l}\text { TLC Strepto- } \\
\text { lidine } \\
\text { determination }\end{array}$} \\
\hline & & & & $\begin{array}{l}\% \text { Strepto- } \\
\text { lidine }\end{array}$ & $\beta$-Lysine & \\
\hline \multirow[t]{16}{*}{ Knowns } & LLAB $664 \alpha$ & 6 & 2 & 0 & 0 & $\mathrm{No}^{\circ}$ \\
\hline & LLAB664 $\beta$ & 5 & 4 & 5.6 & 0 & Yes \\
\hline & LLAC541 & 5 & 2 & 9.1 & 0 & Yes \\
\hline & Streptothricin & 5 & 6 & 13.3 & 13.9 & Yes \\
\hline & Boseimycin & 3 & 3 & - & - & - \\
\hline & Spectinomycin & 1 & -2 & - & - & - \\
\hline & Myomycin & 3 & 0 & - & - & - \\
\hline & Bu 1975 & 2 & - & - & - & - \\
\hline & Butirosin & 2 & - & - & - & - \\
\hline & Paromomycin & 2 & - & - & - & - \\
\hline & Lividomycin & 3 & - & - & - & - \\
\hline & Hygromycin B & 2 & - & - & - & - \\
\hline & Neomycin & 2 & 0 & - & - & - \\
\hline & Streptomycin & 3 & 0 & - & - & - \\
\hline & Edeine & 2 & 2 & - & - & - \\
\hline & Gentamicin & 3 & - & - & - & - \\
\hline \multirow[t]{10}{*}{ Unknowns } & $\mathrm{BC}-1155^{*}$ & 5 & $>6$ & 2.8 & 6.0 & Yes \\
\hline & AAA-037* & 4 & $>6$ & 3.1 & 4.6 & Yes \\
\hline & BC-2875* & 4 & 5 & 10.4 & 17.9 & Yes \\
\hline & AAA-004* & 5 & $>4$ & 1.2 & 1.2 & Yes \\
\hline & BC-2955* & 5 & $>6$ & 2.2 & 0 & Yes \\
\hline & BC-2984* & 4 & $>4$ & 4.5 & 0 & Yes \\
\hline & BC-1900 & 1 & -2 & 0 & 0 & No \\
\hline & AAA-306 & 2 & 0 & 0 & 0 & No \\
\hline & AAA-200* & 3 & 1 & 13.6 & 5.9 & Yes \\
\hline & BCI-5, 6,8 & 3 & -3 & 0 & 0 & No \\
\hline
\end{tabular}

a Concentration of known antibiotics were $10 \mathrm{mg} / \mathrm{ml}$. Fermentation products of unknown antibiotic contained uncontrolled quantities of antibiotic.

b The difference (fold) between susceptible and resistant strains using two fold dilution disc diffusion test.

* Later on identified as streptothricin group of antibiotics by several criteria.

c Thin-layer chromatography method:

A $4 \mathrm{mg}$ isolate was hydrolyzed by heating overnight in $0.5 \mathrm{ml} 6 \mathrm{~N} \mathrm{HCl}$ at $110^{\circ} \mathrm{C}$ in Glenco pressure tubes and dried in a vacuum. The residual was suspended in $2.5 \mathrm{ml}$ of $\mathrm{H}_{2} \mathrm{O}$ and adjusted to $\mathrm{pH} 7.0$ with $0.5 \mathrm{~N} \mathrm{NH}_{4} \mathrm{OH}$. This solution was applied to IRC-50 $\left(\mathrm{NH}_{4}{ }^{+}\right)$column $(0.8 \times 1.8 \mathrm{~cm})$ and washed with water. The column was eluted with $1 \mathrm{~N} \mathrm{NH}_{4} \mathrm{OH}$ and the eluate was concentrated under vacuum and reconstituted with water. The sample was spotted on $20 \times 20$ Avicel plates. Two different solvent systems were used: Acetonitrile - water-glacial acetic acid (60:40:3) and tert-butanol-glacial acetic acid - $\mathrm{H}_{2} \mathrm{O}$ $(2: 1: 1)$. The plate is dried at room temperature and sprayed with ninhydrin and heated on a hot plate. Streptolidine gives a dull, pale yellow spot which turns deep brown pink.

d An amino acid autoanalyzer was used for amino acid analysis. ${ }^{3)}$

e Contains ninhydrin negative $N$-methyl streptolidine. 
The $B$. subtilis $-B$. mycoides strains were equally susceptible to the streptothricin LL-AB664 $\alpha$. In addition to using known compounds, twenty crude preparations of suspected streptothricin antibiotics produced by unidentified actinomycetes were tested with the S. aureus 209P/Streptomyces $\mathrm{BC}-1143$ and the $E$. coli $\mathrm{K} 802 \mathrm{~N}$ stn $^{\mathrm{R}}$ pairs. The resistant patterns with both systems support the presence of streptothricin in the crude samples. The sensitivity of these two resistant pairs for presumptive detections of streptothricin was confirmed using thin-layer chromatography and amino acid analysis. Samples for TLC were hydrolyzed with $6 \mathrm{~N} \mathrm{HCl}$, neutralized, and components separated using cellulose thin-layer chromatography. Chromatograms were developed with two solvent systems (acetonitrite - water glacial acetic acid (60:40:3) and tert-butanol glacial acetic acid - water $(2: 1: 1))$. These data are shown in Table 2. In every instance where $\beta$-lysine or streptolidine were detected, at least three- to four-fold differences in sensitivity were observed in the E. coli test.

The E. coli $\mathrm{K} 802 \mathrm{~N} / E$. coli $\mathrm{K} 802 \mathrm{~N} s \sin ^{\mathrm{R}}$ pair and TLC system were incorporated as a routine me- thod for presumptive detection of streptothricin antibiotics. After institution of these systems in the screening program, streptothricin antibiotics were detected early, and in turn, eliminated from further study. Of the crude materials presumptively identified as streptothricin by the resistant screen, but not confirmed by TLC method, two compounds were later identified as capreomycin and myomycin. The resistant screen, E. coli $\mathrm{K} 802 \mathrm{~N} / E$. coli $\mathrm{K} 802 \mathrm{~N} s n^{\mathrm{R}}$, has proven extremely dependable and provides a rapid method for recognition of streptothricin antibiotics in crude broths.

\section{References}

1) Eisman, P. C.; W. S. Marsh \& R. L. MAyer: Differentiation of antibiotics by resistant strains. Science 103: 673 674, 1946

2) Stapley, E. O.: Cross-resistance studies and antibiotic identification. Appl. Microbiol. 6: 392 398, 1958

3) Borders, D. B.: Ion-exchange chromatography of streptothricin-like antibiotics. Methods in Enzymology 43: 256 263, 1975 